\title{
Molecular hydrogen generated by elemental magnesium supplementation alters rumen fermentation and microbiota in goats
}

\author{
Min Wang ${ }^{1,2}$, Rong Wang ${ }^{1,3}$, XiuMin Zhang ${ }^{1}$, Emilio M. Ungerfeld ${ }^{4}$, Donglei Long ${ }^{1,3}$, HongXiang Mao ${ }^{1,3}$, \\ JinZhen Jiao $^{1}$, Karen A. Beauchemin ${ }^{5}$ and Zhiliang Tan ${ }^{1,2 *}$ \\ ${ }^{1}$ Key Laboratory for Agro-Ecological Processes in Subtropical Region, National Engineering Laboratory for Pollution Control \\ and Waste Utilization in Livestock and Poultry Production, Institute of Subtropical Agriculture, The Chinese Academy of \\ Sciences, Changsha, Hunan 410125, People's Republic of China \\ ${ }^{2}$ Hunan Co-Innovation Center of Animal Production Safety (CICAPS), Changsha, Hunan 410128, People's Republic of China \\ ${ }^{3}$ College of Animal Science and Technology, Hunan Agricultural University, Changsha 410128, People's Republic of China \\ ${ }^{4}$ Instituto de Investigaciones Agropecuarias (INIA) Carillanca, Temuco 8340422, Chile \\ ${ }^{5}$ Lethbridge Research and Development Centre, Agriculture and Agri-Food Canada, Lethbridge, Alberta T1J 4B1, Canada \\ (Submitted 8 May 2017 - Final revision received 29 June 2017 - Accepted 24 July 2017 - First published online 20 September 2017)
}

\begin{abstract}
We tested the hypotheses that supplementation of a diet with elemental $\mathrm{Mg}$ increases ruminal dissolved $\mathrm{H}_{2}\left(\mathrm{dH}_{2}\right)$ in rumen fluid, which in turn alters rumen fermentation and microbial community in goats. In a randomised block design, twenty growing goats were allocated to two treatments fed the same basal diet with $1.45 \% \mathrm{Mg}(\mathrm{OH})_{2}$ or $0.6 \%$ elemental $\mathrm{Mg}$. After $28 \mathrm{~d}$ of adaptation, we collected total faeces to measure total tract digestibility, rumen contents to analyse fermentation end products and microbial groups, and measured methane $\left(\mathrm{CH}_{4}\right)$ emission using respiration chambers. Ruminal $\mathrm{Mg}^{2+}$ concentration was similar in both treatments. Elemental $\mathrm{Mg}$ supplementation increased $\mathrm{dH}_{2}$ at $2.5 \mathrm{~h}$ post morning feeding $(+180 \%, P<0 \cdot 001)$. Elemental $\mathrm{Mg}$ supplementation decreased total volatile fatty acid concentration $(-8 \cdot 6 \%, P<0 \cdot 001)$, the acetate:propionate ratio $(-11.8 \%, P<0.03)$ and fungal copy numbers $(-63.6 \%, P=0.006)$, and increased propionate molar percentage $(+11.6 \%, P<0.001)$, methanogen copy numbers $(+47.9 \%, P<0.001)$, dissolved $\mathrm{CH}_{4}(+35.6 \%, P<0.001)$ and $\mathrm{CH}_{4}$ emissions $(+11.7 \%, P=0.03)$, compared with $\mathrm{Mg}(\mathrm{OH})_{2}$ supplementation. The bacterial community composition in both treatments was overall similar. Ruminal $\mathrm{dH}_{2}$ was negatively correlated with acetate molar percentage and fungal copy numbers $(P<0.05)$, and positively correlated with propionate molar percentage and methanogen copy numbers $(P<0.05)$. In summary, elemental $\mathrm{Mg}$ supplementation increased ruminal $\mathrm{dH}_{2}$ concentration, which inhibited rumen fermentation, enhanced methanogenesis and seemed to shift fermentation pathways from acetate to propionate, and altered microbiota by decreasing fungi and increasing methanogens.
\end{abstract}

Key words: Elemental magnesium: Fermentation pathways: Dissolved hydrogen: Methane: Rumen microbiota

Volatile fatty acids (VFA), carbon dioxide $\left(\mathrm{CO}_{2}\right)$ and molecular $\mathrm{H}\left(\mathrm{H}_{2}\right)$ are produced during carbohydrate fermentation by bacteria, protozoa and fungi in the rumen. VFA serve as a major energy source for the host animal ${ }^{(1)}$, with acetate and propionate being the main precursors of fat and glucose, respectively. The main consumers of $\mathrm{H}_{2}$ are methanogenic Archaea, producing methane $\left(\mathrm{CH}_{4}\right)$ as an end product of fermentation, which keeps a low $\mathrm{H}_{2}$ partial pressure in the rumen ${ }^{(2)}$. It is understood that the accumulation of $\mathrm{H}_{2}$, which typically occurs when methanogenesis is inhibited, could hinder the re-oxidation of reduced electron carriers and adversely affect fermentation and fibre digestion ${ }^{(3)}$.

Besides being used as a substrate for methanogenesis, $\mathrm{H}_{2}$ is also involved in VFA production ${ }^{(2,4)}$. This is because different numbers of moles of $\mathrm{H}_{2}$ (or of reducing equivalent pairs in reduced co-factors), are released or incorporated in the production pathway of each VFA. For example, fermentation of $1 \mathrm{~mol}$ of glucose to acetate releases $4 \mathrm{~mol}$ of electron pairs, most of which are transferred to protons to form $\mathrm{H}_{2}$. In contrast, fermentation of glucose to propionate involves $\mathrm{H}_{2}$ or metabolic $\mathrm{H}$ incorporation ${ }^{(2)}$. When animals are switched from fibrous to starchy diets, or rumen methanogenesis is inhibited, dissolved $\mathrm{H}_{2}\left(\mathrm{dH}_{2}\right)$ in the rumen elevates, and, as expected from the stoichiometry of acetate and propionate production, fermentation shifts from acetate to propionate ${ }^{(5-7)}$.

However, when the effect of direct addition of $\mathrm{H}_{2}$ as gas (gaseous $\mathrm{H}_{2}, \mathrm{gH}_{2}$ ) has been studied in in vitro batch cultures $^{(8-10)}$ and in vivo ${ }^{(11)}$, the results observed in acetate and

Abbreviations: $\mathrm{CH}_{4}$, methane; $\mathrm{CO}_{2}$, carbon dioxide; $\mathrm{dCH}_{4}$, dissolved $\mathrm{CH}_{4} ; \mathrm{dCO}_{2}$, dissolved carbon dioxide; dH $\mathrm{H}_{2}$, dissolved $\mathrm{H}_{2}$; gCO , gaseous $\mathrm{CO}_{2}$; gH , gaseous $\mathrm{H}_{2} ; \mathrm{H}_{2}$, molecular hydrogen; OUT, operational taxonomic units; VFA, volatile fatty acid.

* Corresponding author: Z. Tan, fax +86731 4612685, email zltan@isa.ac.cn 
propionate do not fully agree with that rationale. In batch cultures, Broudiscou et al. ${ }^{(12)}$ found that the effect of an initial 0.5 or $1 \mathrm{kPa} \mathrm{gH}_{2}$ headspace on acetate and propionate production depended on the inoculum used, and when using an inoculum adapted to a fibrous substrate, $\mathrm{gH}_{2}$ addition unexpectedly increased acetate and decreased propionate. Similarly, Patra \& $\mathrm{Yu}^{(8)}$ found that including $\mathrm{gH}_{2}$ in the initial culture headspace unexpectedly resulted in lower propionate molar percentage. Similarly, Qiao et al. ${ }^{(10)}$ found that increasing $\mathrm{gH}_{2}$ in the headspace of batch cultures actually increased acetate molar percentage and the acetate:propionate ratio, and decreased propionate molar percentage. Infusion of $\mathrm{gH}_{2}$ in the rumen of dairy cows did not result in changes in total VFA concentration or VFA profile ${ }^{(11)}$. The effect of $\mathrm{gH}_{2}$ on $\mathrm{dH}_{2}$ concentration was not reported in those studies. Given that $\mathrm{dH}_{2}$ and $\mathrm{gH}_{2}$ have been shown not to be at equilibrium in vitro ${ }^{(13)}$ and in vivo ${ }^{(14)}$, and that the form of $\mathrm{H}_{2}$ available to microbes is $\mathrm{dH}_{2}$ rather than $\mathrm{gH}_{2}$, we propose that the role of $\mathrm{H}_{2}$ on fermentation needs further examination by studying the effect of $\mathrm{dH}_{2}$ addition.

Our first hypothesis for this study using goats as the experimental ruminant model was that $\mathrm{dH}_{2}$ could be increased through supplementing elemental $\mathrm{Mg}$ to the diet, as elemental $\mathrm{Mg}$ would react with water in rumen fluid releasing $\mathrm{H}_{2}: \mathrm{Mg}+$ $2 \mathrm{H}_{2} \mathrm{O} \rightarrow \mathrm{Mg}(\mathrm{OH})_{2}+\mathrm{H}_{2}{ }^{(15)}$. Our second hypothesis was that increased $\mathrm{dH}_{2}$ would alter rumen fermentation and the microbial community composition.

\section{Methods}

All animal procedures were approved by the Animal Care Committee, Institute of Subtropical Agriculture, the Chinese Academy of Sciences (CAS), Changsha, China.

\section{Goats and diets}

A randomised block design with two treatments was used to investigate the effects of $\mathrm{H}_{2}$ generated by the reaction of elemental Mg with water in the rumen fluid of goats. In all, twenty growing Xiangdong black male goats (mean initial body weight $=20 \cdot 3(\mathrm{sD} 3.42) \mathrm{kg})$ were allocated to ten blocks according to body weight and $\mathrm{CH}_{4}$ emission ( $\mathrm{g} / \mathrm{kg}$ DM intake) measured in a preliminary experiment (unpublished results). Two treatments were formulated with equal dietary Mg content: basal diet plus $1.45 \%$ (DM basis) $\mathrm{Mg}(\mathrm{OH})_{2}$ powder (99\% purity; Beijing Taizejiaye Technology Development Co., Ltd) for the control group and basal diet with $0.60 \%$ (DM basis) elemental Mg powder (99\% purity; Beijing Taizejiaye Technology Development Co., Ltd) for the hypothesised elevated $\mathrm{dH}_{2}$ group. In a preliminary experiment (unpublished results), these treatments had been shown to be harmless to the health of goats. Each block of animals contained two goats and each goat within a block was randomly assigned to one of the two dietary treatments.

Goats were kept in individual pens and had free access to fresh water. The diet was formulated to meet 1.4 times maintenance requirements of goats. The composition of the basal diet is shown in Table 1. Dietary forage and concentrate were
Table 1. Ingredients and chemical composition of the basal diet offered to goats (g/kg DM)

\begin{tabular}{lc}
\hline Items & Diet \\
\hline Dietary ingredient (g/kg DM) & \\
Forage & \\
$\quad$ Rice straw & 300 \\
Concentrate & \\
$\quad$ Soyabeans & 54 \\
Maize & 304 \\
Wheat bran & 290 \\
CaCO 3 & 5 \\
Fat & 11 \\
NaCl & 5 \\
Urea & 11 \\
Premix & 20 \\
Chemical composition (g/kg DM) & \\
DM & 960 \\
Organic matter & 912 \\
Ash & $88 \cdot 3$ \\
Crude protein & 150 \\
Starch & 262 \\
Neutral detergent fibre & 312 \\
Acid detergent fibre & 186 \\
Diethyl ether extract & $35 \cdot 0$ \\
Gross energy (MJ/kg) & $18 \cdot 2$ \\
Prith & \\
\hline
\end{tabular}

* Premix was formulated to provide the following (per kg of premix): $400 \mathrm{~g}$ of $\mathrm{NaHCO}_{3}$, $2 \mathrm{~g}$ of Fe, $1 \mathrm{~g}$ of $\mathrm{Cu}, 0.01 \mathrm{~g}$ of $\mathrm{Co}, 0.05 \mathrm{~g}$ of I, $6.6 \mathrm{~g}$ of $\mathrm{Mn}, 4.4 \mathrm{~g}$ of $\mathrm{Zn}, 0.003 \mathrm{~g}$ of Se, $333 \mathrm{mg}$ of retinol, $5 \mathrm{mg}$ of cholecalciferol, $838 \mathrm{mg}$ of $a$-tocopherol.

not mixed, and both forage and concentrate were offered separately, each divided into two equal portions at 08.00 and 17.00 hours. Diets were offered for a $28-\mathrm{d}$ adaptation period before conducting measurements. The elemental $\mathrm{Mg}$ and $\mathrm{Mg}$ $(\mathrm{OH})_{2}$ supplements were mixed with the concentrate fraction immediately before feeding to avoid the reaction with water in the environment, and the concentrate fraction containing the elemental $\mathrm{Mg}$ and $\mathrm{Mg}(\mathrm{OH})_{2}$ supplements was eaten completely within approximately $1 \mathrm{~h}$. During the initial $10 \mathrm{~d}$ of adaptation to diets, feed was offered ad libitum targeting 5\% refusals. The amount of feed allocated daily during the next $18 \mathrm{~d}$ of adaptation was adjusted to $100 \%$ of the DM intake previously measured in order to minimise feed selection. The refusals, when present, were collected and analysed to determine the actual nutrient intakes.

\section{Nutrient digestibility}

Nutrient digestibility was determined over a 5-d period from days 29 to 33. Total faeces and urine were collected twice daily, weighed and mixed daily. A subsample (approximately 1\%) was frozen immediately at $-20^{\circ} \mathrm{C}$, and another subsample (approximately $1 \%$ ) was acidified using $10 \%(\mathrm{w} / \mathrm{w}) \mathrm{H}_{2} \mathrm{SO}_{4}$ to prevent $\mathrm{N}$ loss and then frozen immediately at $-20^{\circ} \mathrm{C}$. The faeces samples were later dried at $60^{\circ} \mathrm{C}$ for $48 \mathrm{~h}$ in a forced-air oven, and ground through a 1-mm screen. The acidified oven-dried samples were used for total $\mathrm{N}$ analysis, whereas non-acidified, oven-dried samples were used for other chemical analyses.

\section{Rumen sampling}

Collection of rumen contents was performed at $0,+2 \cdot 5$ and $+6 \mathrm{~h}$ relative to the commencement of the morning feeding on days 
34 and 35. Rumen contents $(300 \mathrm{ml})$ were collected by oral stomach tubing as described by Wang et al. ${ }^{(16)}$, with the initial $100 \mathrm{ml}$ discarded to avoid saliva contamination. The $\mathrm{pH}$ of rumen contents was measured immediately after sampling using a portable pH meter (Starter 300; Ohaus Instruments Co. Ltd). Two subsamples of $35 \mathrm{ml}$ each were immediately transferred into 50-ml plastic syringes for measuring $\mathrm{dH}_{2}$ and dissolved $\mathrm{CH}_{4}$ $\left(\mathrm{dCH}_{4}\right)$ concentration, as described by Wang et al. ${ }^{(13)}$. Two other $35-\mathrm{ml}$ subsamples were immediately frozen at $-80^{\circ} \mathrm{C}$ in liquid $\mathrm{N}_{2}$ for DNA extraction and subsequent microbial analyses. In addition, 2-ml samples of rumen contents were collected and centrifuged at $15000 \mathrm{~g}$ for $10 \mathrm{~min}$ at $4^{\circ} \mathrm{C}$, and $1.5 \mathrm{ml}$ of supernatant was acidified using $0 \cdot 15 \mathrm{ml}$ of $25 \%(\mathrm{w} / \mathrm{v})$ metaphosphoric acid, and stored at $-20^{\circ} \mathrm{C}$ for subsequent measurement of VFA concentration. The remaining sample of rumen contents was stored at $-20^{\circ} \mathrm{C}$ for the measurements of ammonium $\left(\mathrm{NH}_{4}^{+}\right)$, $\mathrm{Mg}^{2+}$ and glucose concentration.

\section{Methane and carbon dioxide emissions}

$\mathrm{CH}_{4}$ and $\mathrm{CO}_{2}$ emissions were measured in three plexiglass respiration chambers that permitted the goats to see each other, thereby minimising stress. $\mathrm{CH}_{4}$ and $\mathrm{CO}_{2}$ emissions were measured individually for each goat for $48 \mathrm{~h}$ using the protocol of Wang et $a l .{ }^{(17)}$ slightly modified. In brief, during seven periods of $2 \mathrm{~d}$ each, each block of animals containing two goats assigned to different treatments was randomly assigned to a chamber. One goat from each block was then randomly assigned to a measurement period, and the second goat from that block was placed in the same chamber in the subsequent period. Within the chamber, the goats were restrained with free access to a feed bin and drinking water. Airflow was maintained under negative pressure (flow rate $=35 \mathrm{~m}^{3} / \mathrm{h}$ ). Outlet gas from the chamber and ambient gas were connected to a multiport inlet unit of a gas analyser (GGA-30p; Los Gatos Research) for measuring $\mathrm{CH}_{4}$ and $\mathrm{CO}_{2}$ concentration. The cycling time to measure $\mathrm{CH}_{4}$ and $\mathrm{CO}_{2}$ concentration produced in the chamber was $30 \mathrm{~min}$, with $8 \mathrm{~min}$ for analysing gases from each of the three chambers and $6 \mathrm{~min}$ for analysing background environmental concentrations of $\mathrm{CH}_{4}$ and $\mathrm{CO}_{2}$ in incoming air. Daily $\mathrm{CH}_{4}$ and $\mathrm{CO}_{2}$ emissions were calculated using net $\mathrm{CH}_{4}$ and $\mathrm{CO}_{2}$ concentrations and flow rate of air through each chamber at 30-min intervals, and differences between chambers were corrected using the methodology described by McGinn et $a l .{ }^{(18)}$. The chambers were opened twice a day at 08.00 and 18.00 hours to deliver the diets. The chamber cleaning, such as swapping faeces and urine trays, took place during the morning before feeding.

\section{Sample analysis}

All samples of feeds, refusals and faeces were dried and ground to pass through a 1-mm sieve. Contents of DM (method 945.15), organic matter (OM) (method 942.05), crude protein (method 954.01) and diethyl ether extract (method 920.39) were determined according to published methodologies ${ }^{(19)}$. Gross energy was determined using an isothermal automatic calorimeter (5E-AC8018; Changsha Kaiyuan Instruments Co. Ltd). Contents of neutral detergent fibre (NDF) and acid detergent fibre were determined and expressed inclusive of residual $\mathrm{ash}^{(20)}$, and NDF was assayed with the addition of a heat-stable amylase, but without sodium sulphite. The starch content was determined after pre-extraction with ethanol ( $80 \%)$, and glucose released from starch by enzyme hydrolysis was measured using amyloglucosidase ${ }^{(21)}$.

Frozen acidified rumen samples were thawed and centrifuged at $15000 \mathrm{~g}$ for $10 \mathrm{~min}$ at $4^{\circ} \mathrm{C}$, and individual VFA concentrations in the supernatant were measured using GC (Agilent 7890A; Agilent Inc.), according to the method described by Wang et al. ${ }^{(13)}$. The estimated net $\mathrm{H}_{2}$ production relative to the amount of total VFA produced $\left(\mathrm{R}_{\mathrm{NH} 2}\right)$ was estimated according to the stoichiometric equation developed by Wang et $a l^{(16)}$, under the assumption of equal fractional rates of individual VFA absorption. Ammonia and glucose in the supernatant were determined colorimetrically according to the methods of Weatherburn ${ }^{(22)}$ and Nelson ${ }^{(23)}$, respectively. The concentration of $\mathrm{Mg}^{2+}$ in the supernatant was determined by Inductively Coupled Plasma-Optical Emission Spectrometers using Varian 720-ES series (Agilent Inc.).

Dissolved gases were also measured immediately after sampling using the procedure described by Wang et al. ${ }^{(16)}$ with a slight modification. In brief, a 20-ml syringe containing $10 \mathrm{ml}$ of $\mathrm{N}_{2}$ gas was connected to a $50-\mathrm{ml}$ plastic syringe containing $35-\mathrm{ml}$ rumen content samples via polyurethane tubing. The $\mathrm{N}_{2}$ gas was then injected into the $50-\mathrm{ml}$ syringe, and the gases dissolved in the rumen fluid were extracted into the $\mathrm{N}_{2}$ gas phase by vigorously hand shaking for $5 \mathrm{~min}$. Gaseous $\mathrm{H}_{2}$ and $\mathrm{CH}_{4}\left(\mathrm{gCH}_{4}\right)$ concentrations in the gas phase were measured by GC (Agilent 7890A). The $\mathrm{dH}_{2}$ and $\mathrm{dCH}_{4}$ concentrations in the original rumen fluid were calculated using equations described by Wang et al. ${ }^{(13)}$. Gaseous $\mathrm{CO}_{2}\left(\mathrm{gCO}_{2}\right)$ was calculated as the total dissolved gas extracted minus $\mathrm{dCH}_{4}$ extracted, assuming that rumen gases would be composed of $\mathrm{CO}_{2}$ and $\mathrm{CH}_{4}$. Total dissolved $\mathrm{CO}_{2}\left(\mathrm{dCO}_{2}\right)$ concentration in the original rumen fluid $\left(\mathrm{C}_{\mathrm{TdCO}_{2}}, \mathrm{~mol} / \mathrm{l}\right)$ was calculated by combining equations from Wang et $a l^{(16)}$ and Hille et $a l^{(24)}$, and expressed as follows:

$$
\begin{array}{ll}
\mathrm{C}_{\mathrm{TdCO}_{2}} & =\mathrm{C}_{\mathrm{eTdCO}}+V_{g} \mathrm{C}_{\mathrm{gCO}_{2}} /\left(22 \cdot 4 V_{l}\right) \\
\mathrm{C}_{\mathrm{eTdCO}_{2}} & =\alpha_{\mathrm{CO}_{2}} \mathrm{C}_{\mathrm{gCO}_{2}} 10\left(\mathrm{pH}-\mathrm{pK}_{\mathrm{CO}_{2}}\right)+\alpha_{\mathrm{CO}_{2}} \mathrm{C}_{\mathrm{gCO}_{2}} \\
\mathrm{C}_{\mathrm{gCO}_{2}} & =\left(V_{g}-V_{N}-V_{g} C_{g C H_{4}}\right) / V_{g} \\
\alpha_{\mathrm{CO}_{2}} & =\frac{100}{22 \cdot 4 \exp \left(-6 \cdot 8346+1 \cdot 2817\left(10^{4} / T\right)-3 \cdot 7668\left(10^{6} / T^{2}\right)+2 \cdot 997\left(10^{8} / T^{3}\right)\right)}
\end{array}
$$

where $\mathrm{C}_{\mathrm{eTdCO}}$ is the total $\mathrm{dCO}_{2}$ concentration (mol/l) in the rumen fluid at equilibrium after extraction; $\mathrm{C}_{\mathrm{gCO}_{2}}$ the $\mathrm{gCO}_{2}$ concentration (litres/l) measured in the gas phase of the 20-ml syringe at equilibrium after extraction of dissolved gases; $\mathrm{C}_{\mathrm{gCH}_{4}}$ the $\mathrm{gCH}_{4}$ concentration (litres/l) measured in the gas phase of the 20-ml syringe at equilibrium after extraction of dissolved gases; $V_{g}$ the gas volume $(\mathrm{ml})$ at equilibrium after extraction of dissolved gases; $V_{l}$ the volume of liquid $(\mathrm{ml}) ; V_{N}$ the injected $\mathrm{N}_{2}$ gas volume $(10 \mathrm{ml}) ; \mathrm{pK}_{\mathrm{CO}_{2}}$ the dissociation constant of bicarbonate and set to be $6 \cdot 11^{(24)} ; \alpha_{\mathrm{CO}_{2}}$ the Bunsen absorption coefficient (mol/l.atm) for $\mathrm{CO}_{2}^{(25)}$; and $T$ the temperature in $\mathrm{K}\left(273+\right.$ temperature in $\left.{ }^{\circ} \mathrm{C}\right)$. 


\section{Estimation of Gibbs free-energy changes}

Gibbs energy changes $(\Delta G)$ of fermentation reactions (online Supplementary Table S1) were estimated using measured concentrations of metabolites at $0,+2.5$ and $+6 \mathrm{~h}$ relative to the commencement of the morning feeding. Gibbs energy changes of reactions at standard conditions of $298 \mathrm{~K}$ were calculated from standard Gibbs energy of formation of reactants and products, and then adjusted to a rumen temperature of $312 \mathrm{~K}$ $\left(39^{\circ} \mathrm{C}\right)$ using the van't Hoff equation ${ }^{(26)}$. Gibbs energy changes estimated for actual rumen conditions were subsequently adjusted using measured concentrations of soluble metabolites $\left(10^{-\mathrm{pH}}\right.$, glucose, acetate, propionate and butyrate) and dissolved gases $\left(\mathrm{dH}_{2}, \mathrm{dCO}_{2} \text { and } \mathrm{dCH}_{4}\right)^{(14)}$.

\section{Quantitative real-time PCR analyses}

Rumen samples $(2 \mathrm{ml})$ at each of the three sampling time points were pooled and freeze-dried, and then physically disrupted using a bead beater for $1 \mathrm{~min}$. Genomic DNA was extracted using the QIAamp DNA Stool Mini kit (Qiagen) according to the manufacturer's instructions. The quantity of DNA was measured based on absorbance at 260 and $280 \mathrm{~nm}$ using a NanoDrop ND 100 (Nano Drop Technologies). The absolute quantification of total bacteria, protozoa, fungi, methanogens and select bacterial species was measured by quantitative real-time PCR (qPCR) using primers validated in our laboratory (online Supplementary Table S2) ${ }^{(27)}$. Quantitative PCR was performed according to the procedures described by Jiao et $a l{ }^{(27)}$. Final absolute amounts of target groups or species were estimated by relating the $C_{T}$ value to the standard curves and expressed as $\log _{10}$ copies/DM rumen contents. The abundances of six select rumen bacterial species (Ruminococcus albus, R. flavefaciens, Fibrobacter succinogenes, Selenomonas ruminantium, Ruminobacter amylophilus and Prevotella ruminicola) and of genus Prevotella spp. were measured using qPCR and species-specific 16S rRNA gene-targeted primers (online Supplementary Table S2) and expressed relative to the total bacterial DNA. The abundances of each bacterial species and of genus Prevotella spp. were determined using the $\Delta C_{T} \operatorname{method}^{(28)}$

\section{High-throughput sequencing and analysis}

Extracted purified DNA (50 ng) from each rumen sample was subjected to PCR amplification of the V3-V4 region of 16S rRNA gene using universal bacterial primers $338 \mathrm{~F}$ (5'-ACTCCTACG GGAGGCAGCA-3') and $806 \mathrm{R}$ (5'-GGACTACHVGGGTWT CTAAT- $\left.3^{\prime}\right)^{(29)}$. PCR was performed using a GeneAmp ${ }^{\circledR} 9700$ thermal cycler (Applied Biosystems). The PCR products were purified using the AxyPrep ${ }^{\mathrm{TM}}$ DNA Gel Extraction Kit (Axygen Biosciences) according to the manufacturer's instructions and quantified using the QuantiFluor ${ }^{\text {TM_ST }}$ system (Promega). Purified PCR products were high-throughput-sequenced using an IlluminaMiSeq PE300 instrument at Majorbio Bio-Pharm Technology Co., Ltd, using protocols recommended by procedures of Miseq reagent kits v3 (Illumina). Sequences were quality filtered and demultiplexed using exact matches to the supplied DNA barcodes.
Bacterial phylotypes were identified using uclust ${ }^{(30)}$ and assigned to operational taxonomic units (OTU) at $97 \%$ sequence identity. Taxonomic identity of each phylotype was determined using the Greengenes database ${ }^{(31)}$. The resulting OTU were combined into an OTU table that represented abundance of each OTU in each microbial sample. Alpha diversity of bacterial communities was obtained using Mothur version 1.30.1. Similarity between bacterial communities was assessed using the Bray-Curtis distance metric and visualised using principal coordinates (PCOA) analysis.

\section{Statistical analyses}

The statistical model used included dietary treatment and block as fixed effects and sampling day as random effect. When sampling time was included, the model included dietary treatment and block as fixed effects, sampling time as a repeated-measure variable, and the interaction between dietary treatment and sampling time and sampling day as random effects. The best linear or log linear regression was derived between $\mathrm{dH}_{2}$ and concentration of other rumen metabolites using ordinary least squares. Associations between response variables were studied through calculating their Pearson's correlation coefficient $(r)$ and statistical significance. $P \leq 0.05$ was considered significant, and $0.05<P \leq 0.1$ was accepted as a tendency to significance. The SPSS 12.0 software was used for the statistical analyses.

\section{Results}

Although no differences were observed for feed intake and digestibility between both treatments, elemental $\mathrm{Mg}$ supplementation increased $\mathrm{CH}_{4}$ emissions expressed as $\mathrm{g} / \mathrm{d}(+11.7 \%$, $P=0.03)$ and as $\mathrm{g} / \mathrm{kg} \mathrm{OM}$ intake $(+9.87 \%, P=0.03)$ (Table 2 ). No differences were observed in ruminal $\mathrm{Mg}^{2+}$ concentration and $\mathrm{pH}$ between the two treatments (Table 3 ). The $\mathrm{pH}$ was negatively correlated $(r-0.75, P<0.001)$ with ruminal $\mathrm{Mg}^{2+}$ concentration (online Supplementary Fig. S1).

Elemental $\mathrm{Mg}$ supplementation increased the average $\mathrm{dH}_{2}$ $(+95.1 \%, \quad P=0.02)$ and $\mathrm{dCH}_{4}$ concentrations (+39.0\%, $P<0.001$ ) (Table 3). Interactions between treatment and time were observed for $\mathrm{dH}_{2} \quad(P=0.02)$ and $\mathrm{dCH}_{4} \quad(P<0.001)$. Elemental $\mathrm{Mg}$ supplementation increased $\mathrm{dH}_{2}$ only at $+2.5 \mathrm{~h}$ $(+180 \%, P<0.001)$ but not at 0 or +6 h relative to the commencement of the morning feeding, and increased $\mathrm{dCH}_{4}$ at $+2 \cdot 5$ $(+63.4 \%, P<0.001)$ and $+6 \mathrm{~h}(+50.5 \%, P<0.001)$ but not at $0 \mathrm{~h}$ relative to the commencement of the morning feeding (Fig. 1). At $+2.5 \mathrm{~h}$, ruminal $\mathrm{dH}_{2}$ was positively correlated with $\mathrm{dCH}_{4}$ ( $r 0.50, P=0.02$ ) (online Supplementary Fig. S2). Furthermore, ruminal $\mathrm{dH}_{2}$ concentration varied widely among the 10 goats treated with elemental $\mathrm{Mg}$ supplementation, the highest $\mathrm{dH}_{2}$ concentration being $17 \mathrm{mmol} / \mathrm{l}$. When this highest $\mathrm{dH}_{2}$ point was removed, the Pearson's correlation coefficient between $\mathrm{dH}_{2}$ and $\mathrm{dCH}_{4}$ was $0.486(P=0.03$, data not shown $)$.

Elemental Mg supplementation decreased total VFA molar concentration $(-11.6 \%, P<0.001)$, acetate molar percentage $(-3.80 \%, P<0.001)$, the acetate to propionate ratio $(-11.8 \%$, $P<0.03)$ and $\mathrm{R}_{\mathrm{NH} 2}(-42.1 \%, P<0.03)$, and increased propionate molar percentage $(+11.6 \%, P<0 \cdot 001)$ (Table 3). Elemental 
Mg supplementation slightly increased $\Delta \mathrm{G}$ of glucose fermentation to acetate $(P=0.03)$ and to butyrate $(P=0.04)$, did not alter $\Delta \mathrm{G}$ of glucose to $2 / 3$ acetate $+4 / 3$ propionate $(P=0 \cdot 36)$ and tended $(P=0.009)$ to decrease $\Delta \mathrm{G}$ of glucose $+2 \mathrm{H}_{2}$ to propionate at $+2.5 \mathrm{~h}$ relative to the commencement of the morning feeding (Table 4).

Table 2. Feed intake and digestibility, methane $\left(\mathrm{CH}_{4}\right)$ and carbon dioxide $\left(\mathrm{CO}_{2}\right)$ emissions in growing goats fed diets with $1.45 \% \mathrm{Mg}(\mathrm{OH})_{2}$ or $0.6 \%$ elemental magnesium after $28 \mathrm{~d}$ of adaption ( $n 10)$

(Mean values with their standard errors)

\begin{tabular}{|c|c|c|c|c|c|}
\hline \multirow[b]{2}{*}{ Items } & \multicolumn{2}{|c|}{$\mathrm{Mg}(\mathrm{OH})_{2}$} & \multicolumn{2}{|c|}{ Elemental Mg } & \multirow[b]{2}{*}{$P$} \\
\hline & Mean & SE & Mean & SE & \\
\hline \multicolumn{6}{|l|}{ Intake (g/d) } \\
\hline DM & 577 & $17 \cdot 4$ & 573 & $17 \cdot 4$ & 0.46 \\
\hline OM & 524 & $16 \cdot 2$ & 522 & $15 \cdot 9$ & 0.73 \\
\hline $\mathrm{CP}$ & 86.4 & $2 \cdot 60$ & $87 \cdot 3$ & 2.49 & 0.25 \\
\hline NDF & 251 & 7.91 & 247 & $8 \cdot 21$ & 0.21 \\
\hline ADF & 106 & 3.5 & 103 & 3.9 & $0 \cdot 10$ \\
\hline Starch & 175 & $5 \cdot 2$ & 178 & $5 \cdot 0$ & $0 \cdot 11$ \\
\hline GE & 7.67 & 0.229 & $7 \cdot 81$ & 0.219 & $0 \cdot 10$ \\
\hline \multicolumn{6}{|c|}{ Total tract apparent digestibility $(\mathrm{g} / \mathrm{kg})$} \\
\hline OM & 683 & $15 \cdot 3$ & 689 & $9 \cdot 2$ & 0.78 \\
\hline $\mathrm{CP}$ & 779 & $16 \cdot 1$ & 797 & $9 \cdot 7$ & 0.47 \\
\hline NDF & 572 & $26 \cdot 7$ & 591 & $16 \cdot 9$ & 0.57 \\
\hline Starch & 980 & $5 \cdot 8$ & 981 & $5 \cdot 3$ & 0.65 \\
\hline \multicolumn{6}{|l|}{$\mathrm{CH}_{4}$ emissions } \\
\hline$g / d$ & 8.50 & 0.481 & 9.50 & 0.584 & 0.03 \\
\hline g/kg OM intake & $16 \cdot 2$ & 0.85 & $17 \cdot 8$ & 0.71 & 0.03 \\
\hline g/kg OM digested & $23 \cdot 9$ & 1.42 & $25 \cdot 9$ & 0.83 & $0 \cdot 10$ \\
\hline \multicolumn{6}{|l|}{$\mathrm{CO}_{2}$ emissions } \\
\hline $\mathrm{g} / \mathrm{d}$ & 363 & $15 \cdot 0$ & 388 & $18 \cdot 6$ & 0.25 \\
\hline
\end{tabular}

$\mathrm{CP}$, crude protein; NDF, neutral detergent fibre; ADF, acid detergent fibre; GE, gross energy.
Because the hypothesised effect on $\mathrm{dH}_{2}$ was observed only at $+2.5 \mathrm{~h}$ relative to the commencement of the morning feeding, we focused on this time point for studying the effects of elemental $\mathrm{Mg}$ supplementation on the associations between concentration of $\mathrm{dH}_{2}$ and other rumen metabolites. Ruminal $\mathrm{dH}_{2}$ was negatively correlated with total VFA concentration $(r-0.60, P=0.005)$, acetate molar percentage $(r-0.76$, $P<0.001)$, acetate:propionate ratio $(r-0 \cdot 60, P=0.005)$ and $\mathrm{R}_{\mathrm{NH} 2}$ $(r-0.40, P=0.08)$, and positively correlated with propionate molar percentage $(r 0.47, P=0.03)$ at $+2.5 \mathrm{~h}$ relative to the commencement of the morning feeding (online Supplementary Fig. S3). When the greatest $\mathrm{dH}_{2}$ data point was removed, only a trend ( $r-0.39, P=0.09$, data not shown) to a correlation between $\mathrm{dH}_{2}$ and acetate molar percentage at $+2.5 \mathrm{~h}$ was observed.

Elemental Mg supplementation decreased the copy numbers of fungi $(-63.6 \%, P=0.006)$ and the relative abundance of S. ruminantium $(-39.7 \%, P=0.008)$, and increased the copy numbers of methanogens $(+47.9 \%, P<0.001)$ and relative abundance of $R$. flavefaciens $(+71 \%, P=0.02)$ (online Supplementary Table S3). Ruminal $+2 \cdot 5 \mathrm{~h} \mathrm{dH}_{2}$ was negatively correlated with copy numbers of fungi $(r-0.53, P=0.02)$ and the relative abundance of $S$. Ruminantium $(r-0 \cdot 43, P=0 \cdot 05)$, and positively correlated with copy numbers of methanogens ( $r 0.54, P=0.01$ ) (Fig. 2). When the greatest $\mathrm{dH}_{2}$ data point was removed, a significant correlation $(r-0.54, P=0 \cdot 01$, data not shown) between $+2 \cdot 5 \mathrm{~h} \mathrm{dH}_{2}$ and copy numbers of fungi was still observed.

Pyrosequencing of the $16 \mathrm{~S}$ rRNA gene resulted in 38730 (sD 3761) sequences per sample (range of 30525-44554 sequences per sample). Supplementation with elemental $\mathrm{Mg}$ increased community Ace $(P=0.04)$ and bias-corrected Chao $1(P=0.04)$ richness, but did not alter bacterial diversity of

Table 3. Concentration of rumen metabolites in growing goats fed diets with $1.45 \% \mathrm{Mg}(\mathrm{OH})_{2}$ or $0.6 \%$ elemental magnesium after $28 \mathrm{~d}$ of adaption $(n 10)$

(Mean values with their standard errors)

\begin{tabular}{|c|c|c|c|c|c|c|c|}
\hline \multirow[b]{2}{*}{ Items } & \multicolumn{2}{|c|}{$\mathrm{Mg}(\mathrm{OH})_{2}$} & \multicolumn{2}{|c|}{ Elemental Mg } & \multicolumn{3}{|c|}{$P$} \\
\hline & Mean & SE & Mean & SE & Treatment & Time & Treatment $\times$ Time \\
\hline $\mathrm{Mg}^{2+}(\mathrm{mmol} / \mathrm{l})$ & $5 \cdot 71$ & 0.332 & 5.29 & 0.314 & 0.16 & $<0.001$ & 0.39 \\
\hline $\mathrm{pH}$ & $6 \cdot 66$ & 0.027 & 6.64 & 0.034 & 0.31 & $<0.001$ & 0.003 \\
\hline Glucose (mmol/l) & 4.64 & 0.389 & $5 \cdot 28$ & 0.352 & 0.18 & 0.254 & 0.92 \\
\hline \multicolumn{8}{|l|}{ Dissolved gases } \\
\hline $\mathrm{dH}_{2}(\mu \mathrm{mol} / \mathrm{l})$ & 1.02 & 0.121 & 1.99 & 0.415 & 0.02 & $<0.001$ & 0.02 \\
\hline $\mathrm{dCH}_{4}(\mathrm{mmol} / \mathrm{l})$ & 1.05 & 0.045 & 1.46 & 0.058 & $<0.001$ & $<0.001$ & $<0.001$ \\
\hline $\mathrm{dCO}_{2}(\mathrm{mmol} / \mathrm{l})$ & $57 \cdot 4$ & $5 \cdot 82$ & $58 \cdot 3$ & 4.75 & 0.82 & 0.002 & 0.48 \\
\hline \multicolumn{8}{|l|}{ Rumen fermentation } \\
\hline Ammonia (mmol/l) & 7.54 & 0.829 & 8.23 & 0.994 & 0.17 & 0.02 & 0.13 \\
\hline Total VFA (mmol/l) & 98.5 & 2.59 & $90 \cdot 0$ & $2 \cdot 29$ & $<0.001$ & $<0.001$ & 0.85 \\
\hline Acetate:Propionate & 3.38 & 0.060 & 2.98 & 0.087 & $<0.001$ & 0.003 & 0.97 \\
\hline \multicolumn{8}{|c|}{ Individual VFA (mol/100 mol total VFA) } \\
\hline Acetate & 63.1 & 0.62 & $60 \cdot 7$ & 0.77 & $<0.001$ & 0.19 & 0.99 \\
\hline Propionate & $18 \cdot 9$ & 0.25 & $21 \cdot 1$ & 0.43 & $<0.001$ & $<0.001$ & 0.81 \\
\hline Butyrate & 11.9 & 0.61 & $11 \cdot 8$ & 0.62 & 0.91 & 0.69 & 0.99 \\
\hline Valerate & 1.84 & 0.088 & 1.92 & 0.116 & 0.57 & $<0.001$ & 0.65 \\
\hline Iso-butyrate & 1.45 & 0.067 & 1.56 & 0.078 & $0 \cdot 10$ & $<0.001$ & 0.29 \\
\hline Iso-valerate & $2 \cdot 88$ & 0.119 & 3.00 & 0.157 & 0.39 & $<0.001$ & 0.68 \\
\hline \multicolumn{8}{|c|}{ Estimated net $\mathrm{H}_{2}$ production relative to the amount of total VFA produced (mol/mol) } \\
\hline $\mathrm{R}_{\mathrm{NH} 2}$ & 1.29 & 0.008 & $1 \cdot 22$ & 0.012 & $<0.001$ & $<0.001$ & 0.88 \\
\hline
\end{tabular}

$\mathrm{dH}_{2}$, dissolved $\mathrm{H}_{2} ; \mathrm{dCH}_{4}$, dissolved methane; $\mathrm{dCO}_{2}$, dissolved carbon dioxide; VFA, volatile fatty acids. 

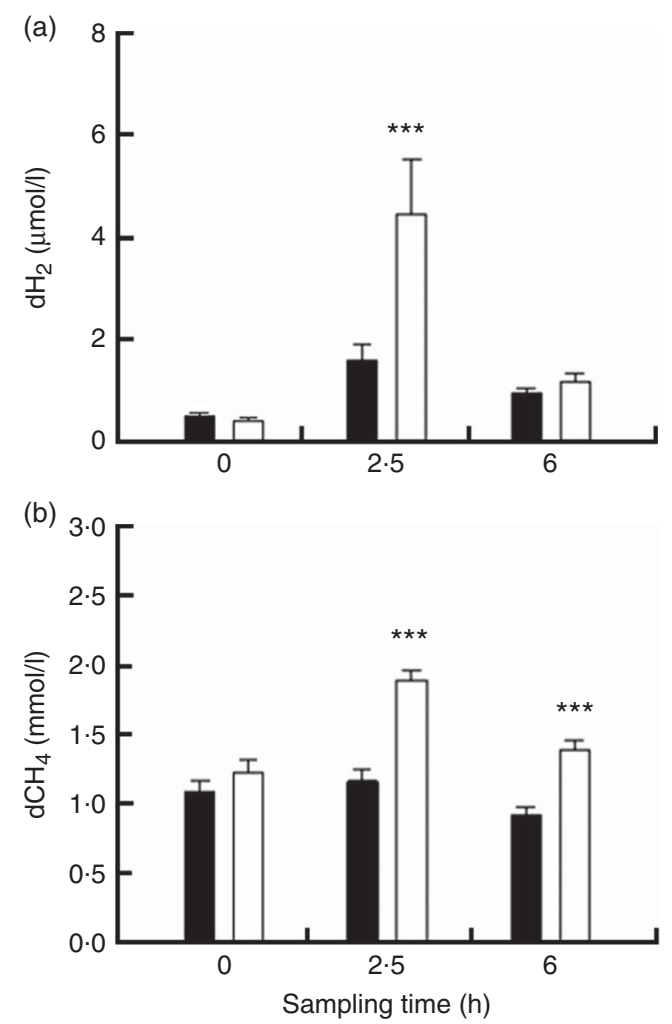

Fig. 1. Dissolved hydrogen $\left(\mathrm{dH}_{2}, \mathrm{a}\right)$ and methane $\left(\mathrm{dCH}_{4}, \mathrm{~b}\right)$ in rumen contents at $0,2.5$ and $6 \mathrm{~h}$ after the commencement of the morning feeding in goats fed diets with $1.45 \% \mathrm{Mg}(\mathrm{OH})_{2}(\square)$ or $0.6 \%$ elemental magnesium ( $\square$ ) after $28 \mathrm{~d}$ of adaption. Values are means ( $n$ 10), with their standard errors represented by vertical bars. ${ }^{\star \star \star} P<0.001$.
Shannon and Simpson index (online Supplementary Table S4). The PC1 and PC2 explained 15.2 and $10.1 \%$ of variation in bacterial OTU, respectively, and the score plot did not show a distinct clustering of goats supplemented with $\mathrm{Mg}(\mathrm{OH})_{2}$ or elemental Mg (online Supplementary Fig. S4). Bacteroidetes and Firmicutes were the most abundant ruminal bacterial phyla, and did not differ between treatments (Table 5). Few differences were observed in the abundance of genera with $>1 \%$ abundance, which are shown in Table 5. Elemental Mg supplementation decreased the abundance of Bacteroidaceae $(P=0.03)$ and increased the abundance of Veillonellaceae $(P=0.06)$ and Succiniclasticum $(P=0.009)$ (Table 5).

\section{Discussion}

$\mathrm{H}_{2}$ is produced during the reaction of elemental $\mathrm{Mg}$ with water: $\mathrm{Mg}+2 \mathrm{H}_{2} \mathrm{O} \rightarrow \mathrm{Mg}(\mathrm{OH})_{2}+\mathrm{H}_{2}$. The $\mathrm{Mg}(\mathrm{OH})_{2}$ so produced would be further hydrolysed in the rumen environment, in a reaction favoured by low $\mathrm{pH}: \mathrm{Mg}(\mathrm{OH})_{2}+2 \mathrm{H}^{+} \rightarrow \mathrm{Mg}^{2+}+2 \mathrm{H}_{2} \mathrm{O}$. Ruminal $\mathrm{Mg}^{2+}$ concentration was thus expected to be $\mathrm{pH}$ dependent, which agreed with the negative association observed between $\mathrm{Mg}^{2+}$ concentration and $\mathrm{pH}$. At all time points, ruminal $\mathrm{Mg}^{2+}$ concentration was similar for both treatments of elemental $\mathrm{Mg}$ and $\mathrm{Mg}(\mathrm{OH})_{2}$ supplementation, which suggests that rumen fluid passage rates to the lower tract were similar for both treatments. The reaction of elemental $\mathrm{Mg}$ with water resulting in $\mathrm{H}_{2}$ formation might have been short-lived, or perhaps incomplete because of rumen outflow of elemental $\mathrm{Mg}$, because $\mathrm{dH}_{2}$ increased at $+2.5 \mathrm{~h}$, but not at $+6 \mathrm{~h}$, relative to the commencement of the morning feeding.

Table 4. Estimated Gibbs energy changes ( $\mathrm{kJ} /$ reaction) of seven reaction pathways in the rumen of goats fed diets $1.45 \% \mathrm{Mg}(\mathrm{OH})_{2}$ or $0.6 \%$ elemental magnesium after $28 \mathrm{~d}$ of adaption $(n 10)^{*}$ (Mean values with their standard errors)

\begin{tabular}{|c|c|c|c|c|c|}
\hline \multirow[b]{2}{*}{ Items } & \multicolumn{2}{|c|}{$\mathrm{Mg}(\mathrm{OH})_{2}$} & \multicolumn{2}{|c|}{ Elemental Mg } & \multirow[b]{2}{*}{$P$} \\
\hline & Mean & SE & Mean & SE & \\
\hline \multicolumn{6}{|c|}{$\mathrm{O} \mathrm{h}$ relative to the commencement of morning feeding } \\
\hline Glucose $\rightarrow 2$ acetate $+4 \mathrm{H}_{2}$ & -337 & 1.32 & -341 & $2 \cdot 14$ & 0.10 \\
\hline Glucose $\rightarrow$ acetate $+1 / 2$ butyrate $+3 \mathrm{H}_{2}$ & -331 & $1 \cdot 13$ & -334 & 1.5 & 0.11 \\
\hline Glucose $\rightarrow$ butyrate $+2 \mathrm{H}_{2}$ & -324 & 1.05 & -327 & 0.97 & 0.15 \\
\hline Glucose $\rightarrow$ acetate + propionate $+\mathrm{H}_{2}$ & -407 & 0.92 & -410 & 1.41 & 0.02 \\
\hline Glucose $\rightarrow 2 / 3$ acetate $+4 / 3$ propionate & -338 & 1.00 & -339 & 0.94 & 0.10 \\
\hline Glucose $+2 \mathrm{H}_{2} \rightarrow 2$ propionate & -350 & 1.68 & -350 & 1.25 & 0.99 \\
\hline $\mathrm{CO}_{2}+4 \mathrm{H}_{2} \rightarrow \mathrm{CH}_{4}$ & $-30 \cdot 3$ & 1.49 & $-27 \cdot 7$ & 1.79 & 0.24 \\
\hline \multicolumn{6}{|c|}{$+2.5 \mathrm{~h}$ relative to the commencement of morning feeding } \\
\hline Glucose $\rightarrow 2$ acetate $+4 \mathrm{H}_{2}$ & -324 & 2.56 & -316 & 3.96 & 0.03 \\
\hline Glucose $\rightarrow$ acetate $+1 / 2$ butyrate $+3 \mathrm{H}_{2}$ & -321 & $2 \cdot 23$ & -314 & 3.24 & 0.03 \\
\hline Glucose $\rightarrow$ butyrate $+2 \mathrm{H}_{2}$ & -319 & 1.93 & -315 & 2.56 & 0.04 \\
\hline Glucose $\rightarrow$ acetate + propionate $+\mathrm{H}_{2}$ & -397 & 1.52 & -393 & $2 \cdot 29$ & 0.07 \\
\hline Glucose $\rightarrow 2 / 3$ acetate $+4 / 3$ propionate & -334 & 0.67 & -333 & 0.77 & 0.36 \\
\hline Glucose $+2 \mathrm{H}_{2} \rightarrow 2$ propionate & -351 & 1.24 & -354 & 1.81 & 0.09 \\
\hline $\mathrm{CO}_{2}+4 \mathrm{H}_{2} \rightarrow \mathrm{CH}_{4}$ & -39.8 & $2 \cdot 14$ & $-46 \cdot 4$ & 3.89 & 0.05 \\
\hline \multicolumn{6}{|c|}{$+6 \mathrm{~h}$ relative to the commencement of morning feeding } \\
\hline Glucose $\rightarrow 2$ acetate $+4 \mathrm{H}_{2}$ & -328 & $1 \cdot 13$ & -329 & $2 \cdot 25$ & 0.67 \\
\hline Glucose $\rightarrow$ acetate $+1 / 2$ butyrate $+3 \mathrm{H}_{2}$ & -324 & $1 \cdot 15$ & -325 & 1.93 & 0.67 \\
\hline Glucose $\rightarrow$ butyrate $+2 \mathrm{H}_{2}$ & -321 & 1.22 & -322 & 1.67 & 0.68 \\
\hline Glucose $\rightarrow$ acetate + propionate $+\mathrm{H}_{2}$ & -401 & 0.79 & -402 & $1 \cdot 18$ & 0.50 \\
\hline Glucose $\rightarrow 2 / 3$ acetate $+4 / 3$ propionate & -335 & 0.76 & -336 & 0.51 & 0.52 \\
\hline Glucose $+2 \mathrm{H}_{2} \rightarrow 2$ propionate & -350 & $1 \cdot 23$ & -350 & $1 \cdot 29$ & 0.96 \\
\hline $\mathrm{CO}_{2}+4 \mathrm{H}_{2} \rightarrow \mathrm{CH}_{4}$ & $-37 \cdot 0$ & $1 \cdot 24$ & $-36 \cdot 0$ & $2 \cdot 27$ & 0.70 \\
\hline
\end{tabular}

* Water is omitted for simplicity. 
(a)

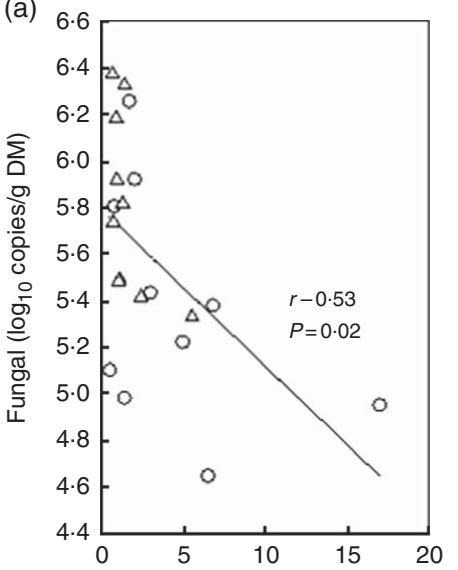

(b)

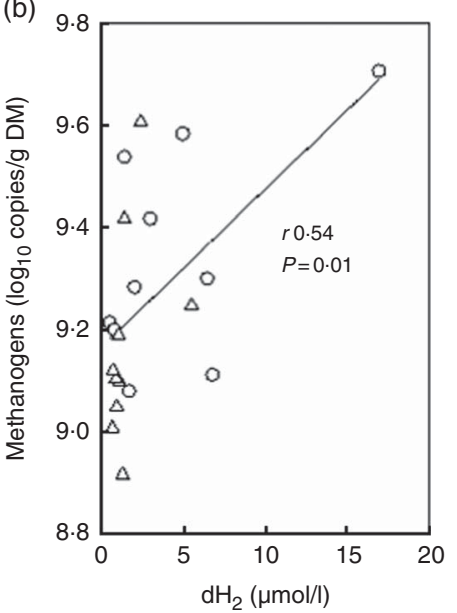

(c)

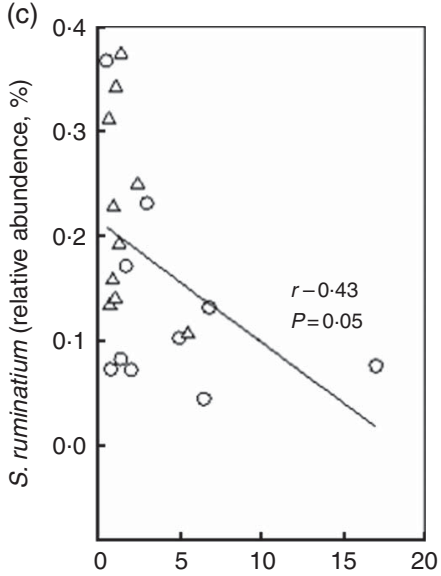

Fig. 2. Relationships between $2.5 \mathrm{~h}$ post-feeding dissolved hydrogen $\left(\mathrm{dH}_{2}\right)$ and select microorganisms $(a$, copy number of fungi; $b$, copy number of methanogens; c, relative abundance of Selenomonas ruminantium), as determined by RT-PCR, in goats $(n 10)$ fed diets with $1.45 \% \mathrm{Mg}(\mathrm{OH})_{2}$ or $0.6 \%$ elemental $\mathrm{Mg}$ after $28 \mathrm{~d}$ of adaption. Each point represents one goat, with a total of 20 data points. $\triangle, \mathrm{Mg}(\mathrm{OH})_{2}$ treatment; $\mathrm{O}$, elemental magnesium treatment.

Table 5. Select bacterial phyla and genera, as determined by $16 \mathrm{~S}$ rRNA pyrosequencing, in the rumen contents of growing goats fed diets with $1.45 \% \mathrm{Mg}(\mathrm{OH})_{2}$ or $0.6 \%$ elemental magnesium after $28 \mathrm{~d}$ of adaption $(n 10)^{*}$ (Mean values with their standard errors)

\begin{tabular}{|c|c|c|c|c|c|c|}
\hline \multirow[b]{3}{*}{ Phyla } & \multirow[b]{3}{*}{ Genera } & \multicolumn{4}{|c|}{$\%$ of sequences } & \multirow[b]{3}{*}{$P$} \\
\hline & & \multicolumn{2}{|c|}{$\mathrm{Mg}(\mathrm{OH})_{2}$} & \multicolumn{2}{|c|}{ Elemental Mg } & \\
\hline & & Mean & SE & Mean & SE & \\
\hline \multirow[t]{2}{*}{ Bacteroidetes } & & $63 \cdot 8$ & 2.96 & $62 \cdot 1$ & 2.09 & 0.61 \\
\hline & Bacteroidaceae $\dagger$ & 0.871 & 0.139 & 0.532 & 0.109 & 0.03 \\
\hline \multirow[t]{3}{*}{ Firmicutes } & & $26 \cdot 2$ & 2.54 & $28 \cdot 3$ & 2.49 & 0.57 \\
\hline & Veillonellaceaeł & 0.486 & 0.142 & 0.883 & 0.198 & 0.06 \\
\hline & Succiniclasticum & 0.987 & 0.217 & 2.88 & 0.556 & 0.009 \\
\hline
\end{tabular}

* Only the most abundant phyla and the genera that differed $(P<0.10)$ between treatments are shown. † Unknown genera within family Bacteroidaceae.

$\ddagger$ Unknown genera within family Veillonellaceae.

It is understood that ruminal $\mathrm{H}_{2}$ accumulation hampers the oxidation of reduced electron carriers, such as $\mathrm{NADH}$, to form $\mathrm{H}_{2}$, leading to impaired glycolysis, decreased microbial ATP generation and fibre degradation in the rumen ${ }^{(32)}$. However, the rumen microbial ecosystem might exhibit the capability to cope with elevated $\mathrm{H}_{2}$. Previous in vivo studies indicated that $\mathrm{H}_{2}$ accumulation under methanogenesis inhibition did not affect feed intake, total tract digestibility and meat or milk production in ruminants $^{(7,33,34)}$. In the current study, we also did not find differences in feed intake and digestibility in goats fed diets supplemented with elemental $\mathrm{Mg}$ and $\mathrm{Mg}(\mathrm{OH})_{2}$, but elevated $\mathrm{dH}_{2}$ resulting from elemental $\mathrm{Mg}$ supplementation decreased total VFA concentration in the rumen, which suggests that fermentation might have been impaired by elevated rumen $\mathrm{dH}_{2}$. At first sight, it is difficult to reconcile the lack of effect of elevated $\mathrm{dH}_{2}$ on digestibility with its negative effects on total VFA concentration. However, both measurements are proxies of digestion and fermentation events. We measured apparent overall tract digestibility, but any changes in microbial biomass in faeces could have masked differences in true overall digestibility. Similarly, we measured VFA concentration in the rumen, but we did not measure actual fluxes of VFA production. A more complete understanding of the effects of elevated $\mathrm{dH}_{2}$ would require a more in-depth study of the dynamics of digestion, microbial biomass production and fluxes of VFA production in the rumen.

The rumen VFA profile varies widely depending on the types of carbohydrates fermented. Diets rich in readily degraded starch generally stimulate propionate production, whereas on the other hand cellulose is fermented preferentially to acetate $^{(35)}$. These shifts of fermentation pathways are associated with the concentration of ruminal $\mathrm{dH}_{2}^{(5)}$. Lower $\mathrm{dH}_{2}$ facilitates $\mathrm{H}_{2}$ generation through acetate production, whereas greater $\mathrm{dH}_{2}$ facilitates the disposition of electrons derived from fermentation into propionate production ${ }^{(2)}$. In this study, we confirmed rumen $\mathrm{dH}_{2}$ as a direct effector of the shift of glucose fermentation pathways, as elevation of $\mathrm{dH}_{2}$ caused by elemental $\mathrm{Mg}$ supplementation decreased acetate molar percentage and increased propionate molar percentage. This study allowed isolating the effects of elevated $\mathrm{dH}_{2}$ on fermentation from other effects caused by changes in the diet.

Elevated $\mathrm{dH}_{2}$ facilitated electron-incorporating glucose fermentation pathways, which agreed with the negative correlation between $\mathrm{dH}_{2}$ and $\mathrm{R}_{\mathrm{NH} 2}$. The shifts in fermentation pathways caused by elevated $\mathrm{dH}_{2}$ resulting from elemental $\mathrm{Mg}$ 
supplementation also agreed with the effects of elemental $\mathrm{Mg}$ supplementation on $\Delta G$ of the main fermentation pathways. The $\Delta \mathrm{G}$ of glucose fermentation to acetate and $\mathrm{H}_{2}$ was increased, and to propionate was decreased, by elemental $\mathrm{Mg}$ supplementation, along with the observed elevated $\mathrm{dH}_{2}$. These results were in agreement with our previous study in dairy cows fed four types of carbohydrates ${ }^{(5)}$. The magnitude of the effects of elemental $\mathrm{Mg}$ supplementation on $\Delta \mathrm{G}$ of most rumen pathways at $+2.5 \mathrm{~h}$ relative to the commencement of the morning feeding were rather small, which suggested that stimulation of pathways incorporating $\mathrm{H}_{2}$ might have taken place through more favourable kinetics of $\mathrm{H}_{2}$ uptake rather than through thermodynamic changes.

Changes in the composition of the rumen microbial community when $\mathrm{gH}_{2}$ accumulates as a consequence of methanogenesis inhibition have been demonstrated ${ }^{(6,7,36)}$. In dairy cows fed four types of carbohydrates, greater $\mathrm{dH}_{2}$ was associated with less acetate and lower number of $\mathrm{H}_{2}$ producers such as anaerobic fungi ${ }^{(5)}$. In that study, however, the concentration of $\mathrm{dH}_{2}$ was a consequence of the type of carbohydrate supplemented, and therefore changes in variables other than $\mathrm{dH}_{2}$ resulting from the dietary changes could have also influenced the abundance of microbial groups. To our knowledge, the present study was the first investigation on how elevated $\mathrm{dH}_{2}$ resulting from a non-fermentative source affected rumen microbiota, and we found that elevated $\mathrm{dH}_{2}$ generated by elemental Mg supplementation greatly decreased $(-63.6 \%)$ the copy numbers of fungi. Decreased fungal numbers did not adversely affect fibre degradation, which might indicate that other fibrolytic organisms, such as $R$. flavefaciens, might have compensated for the negative effects of elemental $\mathrm{Mg}$ on fungi. $R$. flavefaciens produces $\mathrm{H}_{2}$, but also succinate as a major product ${ }^{(37,38)}$, and it would be possible that $R$. Flavefaciens shifted fermentation towards succinate production under elevated $\mathrm{H}_{2}$ resulting from elemental Mg supplementation. That said, the relative abundance of $R$. flavefaciens was small, which casts doubt on the influence it might have had on fibre digestion.

The impact of increased $\mathrm{dH}_{2}$ generated by supplementation with elemental $\mathrm{Mg}$ on the rumen bacterial community composition was further analysed using high-throughput sequencing. Supplementation with elemental Mg increased species richness in terms of Ace and Chao 1 diversity, although total copy numbers of bacteria were similar for both treatments. However, the PCOA score plot indicated that ruminal bacterial community was not distinctly different between both treatments. In a previous study, elevated $\mathrm{H}_{2}$ was associated with increased Bacteroidetes: Firmicutes ratio when methanogenesis was inhibited by chloroform-cyclodextrin ${ }^{(39)}$. However, in the present study, elemental $\mathrm{Mg}$ supplementation decreased the abundance of family Bacteroidaceae, but did not alter the abundance of Bacteroidetes and Firmicutes. An interesting result was that genus Succiniclasticum, which belongs to family Firmicutes and is involved in converting succinate to propionate ${ }^{(40)}$, was 2 -fold more abundant in goats that received elemental Mg supplementation. This result was in agreement with the increased propionate molar percentage in the rumen when $\mathrm{dH}_{2}$ concentration was increased by elemental $\mathrm{Mg}$ supplementation. In contrast, an unexpected observation was that elemental $\mathrm{Mg}$ supplementation and elevated $\mathrm{dH}_{2}$ decreased the abundance of $S$. ruminantium, an important propionateproducing bacterium in the rumen ${ }^{(41)}$. The important increase in Succiniclasticum abundance might have compensated for the decreased abundance of $S$. ruminantium to produce propionate in this study, if in goats supplemented elemental Mg succinate conversion to propionate limited propionate production.

$\mathrm{H}_{2}$ and $\mathrm{CO}_{2}$ are the main substrates for methanogenesis in the rumen, and the majority of $\mathrm{H}_{2}$ produced from carbohydrate fermentation is used in $\mathrm{CH}_{4}$ production ${ }^{(42)}$. In our study, we found that elemental $\mathrm{Mg}$ supplementation increased $\mathrm{dCH}_{4}$ concentration, the copy number of methanogens and $\mathrm{CH}_{4}$ emissions, indicating that increased $\mathrm{dH}_{2}$ generated by elemental $\mathrm{Mg}$ supplementation promoted $\mathrm{CH}_{4}$ production in the rumen of goats. Olijhoek et al. ${ }^{(11)}$ also reported that short-term infusion of $\mathrm{H}_{2}$ into the rumen increased $\mathrm{CH}_{4}$ production. Furthermore, we estimated that elemental Mg supplementation decreased $\Delta \mathrm{G}$ of methanogenesis at $+2.5 \mathrm{~h}$ after the commencement of the morning feeding, indicating that elevated $\mathrm{dH}_{2}$ would have thermodynamically favoured growth and metabolism of methanogens at that time point. Dissolved $\mathrm{H}_{2}$ concentration was positively correlated with copy numbers of methanogens, but not with $\mathrm{CH}_{4}$ emissions. This suggests that ruminal $\mathrm{dH}_{2}$ might have exceeded the capacity of methanogens to take up $\mathrm{H}_{2}$ in the treatment with elemental $\mathrm{Mg}$ supplementation, so that methanogenic population and activity might have been limiting for $\mathrm{CH}_{4}$ generation in the rumen.

In summary, goats adapted to elevated ruminal $\mathrm{dH}_{2}$ generated by elemental Mg supplementation had lower rumen total VFA concentration, copy number of fungi and greater propionate molar percentage and $\mathrm{CH}_{4}$ emissions when compared with goats fed the control diet supplemented with $\mathrm{Mg}(\mathrm{OH})_{2}$. Elevation of ruminal $\mathrm{dH}_{2}$ concentration seemed to inhibit rumen fermentation and altered fermentation pathways and some microbial groups, without affecting total tract digestibility. Effects of extra $\mathrm{H}_{2}$ obtained by supplementing elemental $\mathrm{Mg}$ were short-lived, because elevated $\mathrm{dH}_{2}$ had returned to control concentration by $+6 \mathrm{~h}$ relative to the commencement of the morning feeding. Furthermore, the extent of elevated ruminal $\mathrm{dH}_{2}$ concentration caused by elemental $\mathrm{Mg}$ supplementation varied widely among the ten goats, and the goat with the greatest $\mathrm{dH}_{2}$ concentration $(17 \mathrm{mmol} / \mathrm{l})$ also had the greatest methanogen population and the lowest VFA concentration, acetate molar percentage, acetate:propionate ratio and copy number of fungi. This study provides insights on the effects of elevated $\mathrm{dH}_{2}$ on fermentation in the rumen and methanogenesis, although high dietary $\mathrm{Mg}$ concentration in both treatments might have altered the availability of other minerals and exerted some postabsorptive effects in goats. More studies with sustained and consistent elevated $\mathrm{dH}_{2}$ are needed to further elucidate how elevated $\mathrm{dH}_{2}$ concentration affects the rumen ecosystem, fermentation and digestion.

\section{Acknowledgements}

This work was supported by National Natural Science Foundation of China (grant nos 31561143009, 31320103917 and 31472133), National key research and development program of China (grant no. 2016YFD0500504), Youth Innovation Promotion Association 
CAS (2016327), China Agriculture Research System (grant no. CARS-37) and Hunan province science and technology plan (grant no. 2015WK3043)

M. W., R. W., H. X. M., D. L. L. and X. M. Z. conducted the research; M. W., R. W. and E. M. U. analysed the data; and M. W., E. M. U., K. A. B and Z. L. T. wrote the paper. M. W. and Z. L. T. designed the research and had primary responsibility for the final content. All authors read and approved the final manuscript.

The authors declare that there are no conflicts of interest.

\section{Supplementary material}

For supplementary material/s referred to in this article, please visit https://doi.org/10.1017/S0007114517002161

\section{References}

1. Vyas D, McGinn SM, Duval SM, et al. (2016) Effects of sustained reduction of enteric methane emissions with dietary supplementation of 3-nitrooxypropanol on growth performance of growing and finishing beef cattle1. J Anim Sci $\mathbf{9 4}$, 2024-2034.

2. Janssen PH (2010) Influence of hydrogen on rumen methane formation and fermentation balances through microbial growth kinetics and fermentation thermodynamics. Anim Feed Sci Technol 160, 1-22.

3. Joblin KN (1999) Ruminal acetogens and their potential to lower ruminant methane emissions. Aust J Agric Res 50, 1307-1313.

4. Ungerfeld EM \& Kohn RA (2006) The role of thermodynamics in control of ruminal fermentation. In Ruminant Physiology Digestion, Metabolism and Impact of Nutrition on Gene Expression, Immunology and Stress, pp. 55-85 [K Sejrsen, $\mathrm{T}$ Hvelpund and MO Nielsen, editors]. Wageningen: Wageningen Academic Publishers.

5. Wang M, Wang R, Xie T, et al. (2016) Shifts in rumen fermentation and microbiota are associated with dissolved ruminal hydrogen concentrations in lactating dairy cows fed different types of carbohydrates. J Nutr 146, 1714-1721.

6. Martinez-Fernandez G, Denman SE, Yang C, et al. (2016) Methane inhibition alters the microbial community, hydrogen flow, and fermentation response in the rumen of cattle. Front Microbiol 7, 1122.

7. Mitsumori M, Shinkai T, Takenaka A, et al. (2012) Responses in digestion, rumen fermentation and microbial populations to inhibition of methane formation by a halogenated methane analogue. Br J Nutr 108, 482-491.

8. Patra AK \& Yu Z (2013) Effects of gas composition in headspace and bicarbonate concentrations in media on gas and methane production, degradability, and rumen fermentation using in vitro gas production techniques. J Dairy Sci 96 , 4592-4600.

9. Klop G, Dijkstra J, Dieho K, et al. (2017) Enteric methane production in lactating dairy cows with continuous feeding of essential oils or rotational feeding of essential oils and lauric acid. J Dairy Sci 100, 3563-3575.

10. Qiao JY, Tan ZL, Guan LL, et al. (2015) Effects of hydrogen in headspace and bicarbonate in media on rumen fermentation, methane production and methanogenic population using in vitro gas production techniques. Anim Feed Sci Technol 206, 19-28.

11. Olijhoek DW, Hellwing ALF, Weisbjerg MR, et al. (2016) Effect of short-term infusion of hydrogen on enteric gas production and rumen environment in dairy cows. Anim Prod Sci $\mathbf{5 6}$, 466-471.

12. Broudiscou LP, Offner A \& Sauvant D (2014) Effects of inoculum source, $\mathrm{pH}$, redox potential and headspace di-hydrogen on rumen in vitro fermentation yields. Animal $\mathbf{8}$, 931-937.

13. Wang M, Sun XZ, Janssen PH, et al. (2014) Responses of methane production and fermentation pathways to the increased dissolved hydrogen concentration generated by eight substrates in in vitro ruminal cultures. Anim Feed Sci Technol 194, 1-11.

14. Wang M, Ungerfeld EM, Wang R, et al. (2016) Supersaturation of dissolved hydrogen and methane in rumen of Tibetan sheep. Front Microbiol 7, 850.

15. Ng F, Kittelmann S, Patchett ML, et al. (2016) An adhesin from hydrogen-utilizing rumen methanogen Methanobrevibacter ruminantium $\mathrm{M} 1$ binds a broad range of hydrogen-producing microorganisms. Environ Microbiol 18, 3010-3021.

16. Wang $\mathrm{M}$, Wang $\mathrm{R}$, Janssen $\mathrm{PH}$, et al. (2016) Sampling procedure for the measurement of dissolved hydrogen and volatile fatty acids in the rumen of dairy cows. J Anim Sci $\mathbf{9 4}$, 1159-1169.

17. Wang M, Wang R, Sun X, et al. (2015) A mathematical model to describe the diurnal pattern of enteric methane emissions from non-lactating dairy cows post-feeding. Anim Nutr $\mathbf{1}$, 329-338.

18. McGinn SM, Beauchemin KA, Coates T, et al. (2004) Methane emissions from beef cattle: effects of monensin, sunflower oil, enzymes, yeast, and fumaric acid. J Anim Sci 82, 3346-3356.

19. Association of Official Analytical Chemists (editor) (1995) Official Methods of Analysis, 16th ed. Arlington, VA: AOAC.

20. Van Soest PJ, Robertson JB \& Lewis BA (1991) Symposium: carbohydrate methodology, metabolism and nutritional implications in dairy cattle. Methods for dietary fiber, neutral detergent fiber, and nonstarch polysaccharides in relation to animal nutrition. J Dairy Sci 74, 3583-3597.

21. Kartchner RJ \& Theurer B (1981) Comparison of hydrolysis methods used in feed, digesta, and fecal starch analysis. J Agri Food Chem 29, 8-11.

22. Weatherburn MW (1967) Phenol-hypochlorite reaction for determination of ammonia. Anal Chem 39, 971-974.

23. Nelson N (1944) A photometric adaptation of the Somogyi method for the determination of glucose. J Biol Chem $\mathbf{1 5 3}$, 375-380.

24. Hille KT, Hetz SK, Rosendahl J, et al. (2016) Determination of Henry's constant, the dissociation constant, and the buffer capacity of the bicarbonate system in ruminal fluid. J Dairy Sci 99, 369-385.

25. Carroll JJ, Slupsky JD \& Mather AE (1991) The solubility of carbon-dioxide in water at low-pressure. J Phys Chem Ref Data 20, 1201-1209.

26. Guyader J, Eugène $M$, Doreau $M$, et al. (2017) Tea saponin reduced methanogenesis in vitro but increased methane yield in lactating dairy cows. J Dairy Sci 100, $1845-1855$

27. Jiao J, Lu Q, Tan Z, et al. (2014) In vitro evaluation of effects of gut region and fiber structure on the intestinal dominant bacterial diversity and functional bacterial species. Anaerobe 28, 168-177.

28. Stevenson D \& Weimer P (2007) Dominance of Prevotella and low abundance of classical ruminal bacterial species in the bovine rumen revealed by relative quantification realtime PCR. Appl Microbiol Biotechnol 75, 165-174.

29. Hackmann TJ \& Firkins JL (2015) Electron transport phosphorylation in rumen butyrivibrios: unprecedented ATP yield for glucose fermentation to butyrate. Front Microbiol 6, 622 . 
30. Edgar RC (2010) Search and clustering orders of magnitude faster than BLAST. Bioinformatics 26, 2460-2461.

31. DeSantis TZ, Hugenholtz P, Larsen N, et al. (2006) Greengenes, a chimera-checked 16S rRNA gene database and workbench compatible with ARB. Appl Environ Microbiol 72, 5069-5072.

32. Ungerfeld EM (2015) Shifts in metabolic hydrogen sinks in the methanogenesis-inhibited ruminal fermentation: a metaanalysis. Front Microbiol 6, 37.

33. Hristov AN, Oh J, Giallongo F, et al. (2015) An inhibitor persistently decreased enteric methane emission from dairy cows with no negative effect on milk production. PNAS 112, 10663-10668.

34. Romero-Perez A, Okine EK, McGinn SM, et al. (2015) Sustained reduction in methane production from long-term addition of 3-nitrooxypropanol to a beef cattle diet. J Anim Sci 93, 1780-1791.

35. Bannink A, Kogut J, Dijkstra J, et al. (2006) Estimation of the stoichiometry of volatile fatty acid production in the rumen of lactating cows. $J$ Theol Biol 238, 36-51.

36. Shinkai T, Enishi O, Mitsumori M, et al. (2012) Mitigation of methane production from cattle by feeding cashew nut shell liquid. J Dairy Sci 95, 5308-5316.
37. Stewart CS, Flint HJ \& Bryant MP (1997) The rumen bacteria. In The Rumen Microbial Ecosystem, pp. 10-72 [PN Hobson and CS Stewart, editors]. London: Blackie Academic \& Professional.

38. Philippeau C, Lettat A, Martin C, et al. (2017) Effects of bacterial direct-fed microbials on ruminal characteristics, methane emission, and milk fatty acid composition in cows fed high- or low-starch diets. J Dairy Sci 100, 2637-2650.

39. Fonty G, Joblin K, Chavarot M, et al. (2007) Establishment and development of ruminal hydrogenotrophs in methanogenfree lambs. Appl Environ Microbiol 73, 6391-6403.

40. Scheifinger CC, Linehan B \& Wolin MJ (1975) H2 production by Selenomonas ruminantium in the absence and presence of methanogenic bacteria. Appl Microbiol 29, 480-483.

41. Sawanon S, Koike S \& Kobayashi Y (2011) Evidence for the possible involvement of Selenomonas ruminantium in rumen fiber digestion. FEMS Microbiol Lett 325, 170-179.

42. McAllister TA \& Newbold CJ (2008) Redirecting rumen fermentation to reduce methanogenesis. Aust J Exp Agric $\mathbf{4 8}$, $7-13$.

(1)

